\title{
Relationships Among Raw Materials, Grinding Ratios, and Moisture Content During the Composting Process
}

\author{
Lili Wang1, Quan Huang², Shunli Wang ${ }^{3}$, Guoxue Li ${ }^{4}$ Xingyuan Yang5* \\ ${ }^{1}$ School of Life Science, Anhui University, Hefei, China \\ ${ }^{2}$ College of Animal Technology, Jilin Agricultural University, Changchun, China \\ ${ }^{3}$ Department of Biological and Agricultural Engineering, University of Georgia, Athens, GA, USA \\ ${ }^{4}$ College of Resource and Environmental Engineering, China Agricultural University, Beijing, China \\ ${ }^{5}$ Institute of Physical Science and Information Technology, Institute of Health Science, Anhui University, Hefei, China
}

Received: 23 November 2017

Accepted: 18 December 2017

\begin{abstract}
Grinding materials as a pretreatment contribute to successful composting. Here the grinding ratio of 4 raw materials and compost samples with different maturity degrees were compared and discussed. Results revealed that the highest grinding ratio was obtained when drying the 3 straws into constant weight, but keeping water content around $10 \%$ for sewage sludge. The carbon-to-nitrogen ratio $(\mathrm{C} / \mathrm{N})$ was an important factor impacting the grinding ratio of raw materials except water content. Different straw materials had a decreased grinding ratio from the highest to the lowest in the following order: corn stover $>$ rice straw $>$ wheat straw. The grinding ratio of fermented compost significantly decreased lower than about $50 \%$ when the water content was higher than $30 \%$, whereas no significant difference was observed when the water content was lower than $20 \%$. Compared with original materials, mature compost had a better grinding ratio. Further regression analysis implies that grinding ratio had a negative linear orrelation with total organic carbon (TOC), $\mathrm{C} / \mathrm{N}$, hemicellulose, and cellulose, but no apparent correlation with $\mathrm{pH}, \mathrm{EC}, \mathrm{GI}$, and lignin. Results reported here may provide an efficient way to save energy and investment in the industry production of pellet compost.
\end{abstract}

Keywords: compost, raw materials, grinding ratio, maturity degree, moisture content

\section{Introduction}

Composting as an environmental friendly treatment for efficiently decreasing solid waste volume and recycling organic nutrients is being incorporated into agricultural activities [1-3]. A successful composting

*e-mail: stanleyxingyuan@aliyun.com process usually involves 4 phases: initial or rapid stage of temperature rise; semi-cure or biostabilization, when compost reaches the temperature above $55^{\circ} \mathrm{C}$ [4]; the cure phase, with the start of humification and mineralization of organic matters [5]; and the last period of stability or maturation. Compost quality is generally evaluated by several important physical, chemical, and biological parameters [2, 6-7]. Among the above parameters, the most important include temperature, moisture, $\mathrm{pH}$, 
total organic carbon (TOC), total nitrogen (TN), carbon-to-nitrogen ratio (C:N), germination index (GI), microbiology community variability, etc. [8-9]. Besides the frequently evaluated parameters, grinding ratio is also considered an important parameter in successful composting, especially in pretreatment of raw materials, and post pelletizing of matured compost in commercial production [10]. For example, agricultural residues [11], woody resources [12], or animal beddings [13] are usually shredded into certain sizes before composting. Small particles give more surfaces to composting organisms to enhance the mixing of versatile composting materials and rapider organic residue decomposition during the digestion process [14]. Well mixed materials are beneficial for enhancing ventilation, mass, and heat transfer. In addition, grinding compost is also manipulated before it was made into the commercial pellet product. Pellet compost is one of the best products to supply slow-released nutrients for plants. Moreover, it is more convenient to transport and easier to spread on the farmland by agricultural machinery [15]. It was reported that mature compost can be ground into the size of less than $2 \mathrm{~mm}$ and then pelletized to high-quality compound fertilizer [16].

As mentioned above, grinding materials in pre- and post-treatment of compost is of great importance for determining successful composting and product quality. However, in previous studies, detailed information regarding the grinding ratio have focused on mining engineering [17-18] or feedstock supply [19-20]. The studies proved that compressive force, particle size, and moisture content of materials affect pelletizing. Little attention has been paid to compost characters affecting the grinding ratio. Absalan et al. [16] reported the relationship between pelletizing and water content, pointing out that moisture content of the compost should be reduced to less than $20 \%$ to prevent quality deterioration during long-time storage. Zafari and Kianmehr [21] advised that the optimal moisture content of compost range from $40 \%$ to $43 \%$. Whether different materials have similar grinding ratios and how composting time will affect grinding ratios remain unclear. Some producers grind materials at random size and dry the compost to random water content because no general consensus on grind size and water content was agreed upon. Over-drying and over-grinding increase energy consumption and cost of investment. Therefore, it is valuable to study the optimal grinding ratio of different kinds of composting materials and affected factors.

In a successful aerial composting process, bulking agent (for instance wood chips, wheat straws, corn stovers, etc.) are widely used as skeletons to create air space, and as carbon supply for cell skeletons [7]. The components of raw materials change with complex physical, chemical, and biological reactions during composting, leading to the grinding ratio changing as well. For instance, insoluble fibers, which are the main component of variable straws, are made up of polysaccharides such as cellulose and hemicellulose, which strongly interact with each other and do not dissolve easily in water [22]. The cellular walls of straws are composed of cellulose fibers, together with pectin heteropolymer, hemicellulose, and lignin [23]. The proteins and sugars are easily degradable; lipids and cellulose are little degradable, while the keratins and lignin are slowly degradable [24]. It is hypothesized that the content of cellulose, hemicellulose, and lignin may be the main factors that affect grinding ratio in different materials. Therefore, grinding ratio of different kinds of composting materials (4 raw materials and compost samples with different maturity degrees) and affected factors will be encompassed in this study.

The objectives of this study were to: a) compare grinding ratios of the raw materials of sewage sludge, corn stover, rice straw, and wheat straw in order to optimize water content and b) evaluate the effects of different composting times or maturity degrees on compost grinding ratio. Furthermore, the correlation between compost maturity parameters and grinding ratio was illuminated.

\section{Materials and Methods}

\section{Materials Collection}

Fresh corn stover (CS), rice straw (RS), and wheat straw (WS) were collected from the Science and Technology Training Farm at the end of September 2016 at China Agriculture University. Dewatered sewage sludge (SS) was collected using a plastic bucket from Wujia Wastewater Treatment Plant (Beijing, China). Poultry manure (PM) came from a chicken farm in the

Table 1. Properties of different raw materials for composting.

\begin{tabular}{|c|c|c|c|c|c|c|c|c|}
\hline Compost material & $\begin{array}{c}\text { TOC } \\
\left(\mathrm{g} \cdot \mathrm{kg}^{-1}\right)\end{array}$ & $\begin{array}{c}\mathrm{N} \\
\left(\mathrm{g} \cdot \mathrm{kg}^{-1}\right)\end{array}$ & $\begin{array}{c}\mathrm{P} \\
\left(\mathrm{g} \cdot \mathrm{kg}^{-1}\right)\end{array}$ & $\begin{array}{c}\text { Water content } \\
(\%)\end{array}$ & $\mathrm{C} / \mathrm{N}$ & $\begin{array}{c}\text { Hemicellulose } \\
(\%)\end{array}$ & $\begin{array}{c}\text { Cellulose } \\
(\%)\end{array}$ & $\begin{array}{c}\text { Lignin } \\
(\%)\end{array}$ \\
\hline Sewage sludge & 182.1 & 29.3 & 627 & 40.5 & 6.2 & 2.6 & 7.1 & 6.4 \\
\hline Rice straw & 427.6 & 6.9 & 5.6 & 50.9 & 62.0 & 24.5 & 31.9 & 15.5 \\
\hline Wheat straw & 340.1 & 4.8 & 4.3 & 40.7 & 70.9 & 26.6 & 34.9 & 19.9 \\
\hline Corn stover & 474.2 & 9.3 & 4.7 & 47.0 & 51.0 & 28.6 & 22.8 & 13.2 \\
\hline Poultry manure & 281.5 & 20.5 & 14.3 & 46.5 & 13.7 & - & - & - \\
\hline
\end{tabular}


Table 2. Maturity and quality parameters of compost sampling from different times (Mean $\pm S D, n=3$ ).

\begin{tabular}{|c|c|c|c|c|c|}
\hline Sest items & 0 & 9 & 18 & 27 & 36 \\
\hline $\mathrm{pH}$ & $7.53 \pm 0.10$ & $8.56 \pm 0.02$ & $8.63 \pm 0.07$ & $7.89 \pm 0.02$ & $7.53 \pm 0.12$ \\
\hline EC (mS/cm) & $1.60 \pm 0.01$ & $1.68 \pm 0.03$ & $1.70 \pm 0.08$ & $1.58 \pm 0.02$ & $1.53 \pm 0.05$ \\
\hline GI (\%) & $5.46 \pm 0.15$ & $7.43 \pm 0.21$ & $37.6 \pm 3.90$ & $54.8 \pm 1.50$ & $75.0 \pm 3.80$ \\
\hline TN (\%) & $1.32 \pm 0.07$ & $1.34 \pm 0.04$ & $1.36 \pm 0.02$ & $1.36 \pm 0.02$ & $1.39 \pm 0.01$ \\
\hline TOC (\%) & $34.8 \pm 0.08$ & $33.3 \pm 0.01$ & $28.7 \pm 0.02$ & $27.3 \pm 0.07$ & $26.3 \pm 0.07$ \\
\hline C/N & $26.4 \pm 0.51$ & $24.8 \pm 0.33$ & $21.1 \pm 0.46$ & $20.1 \pm 0.17$ & $18.9 \pm 0.25$ \\
\hline Hemicellulose (\%) & $15.3 \pm 0.40$ & $13.5 \pm 1.20$ & $11.8 \pm 0.71$ & $10.9 \pm 0.10$ & $9.02 \pm 0.14$ \\
\hline Cellulose (\%) & $22.9 \pm 0.04$ & $21.2 \pm 0.24$ & $20.7 \pm 0.09$ & $20.9 \pm 0.06$ & $20.9 \pm 0.04$ \\
\hline Lignin (\%) & $7.90 \pm 0.01$ & $8.08 \pm 0.01$ & $7.52 \pm 0.04$ & $10.0 \pm 0.03$ & $11.2 \pm 0.07$ \\
\hline
\end{tabular}

Department of Animal Technology, China Agriculture University.

\section{Composting and Sampling Methods}

Wheat straws for composting in this study were ground into less than $2 \mathrm{~cm}$ in length by machine, then mixed with poultry manure in the ratio of 1:4 (M:M) to adjust $\mathrm{C} / \mathrm{N}$ ratio to 25 . Extra water was added to adjust water content to $60 \%$. Then the mixed raw material was transferred to a composting bin with $1 \mathrm{~m}$ in height and $1.2 \mathrm{~m}$ in diameter. 21 holes $(4 \mathrm{~cm}$ in diameter) were drilled on the side wall for ventilating. Composting was carried out in a greenhouse for 36 days, and manually turned if the temperature was beyond $60^{\circ} \mathrm{C}$.

The sample was collected from the top $(10 \mathrm{~cm}$ from the pile top), middle ( $50 \mathrm{~cm}$ from the pile top), and bottom (10 $\mathrm{cm}$ from the ground) at days $0,9,18,27$, and 36 . Around $150 \mathrm{~g}$ well-mixed samples were randomly taken according to "S" sampling method with the principle of equivalent and multipoint and put into a plastic zipped bag and stored at $4^{\circ} \mathrm{C}$ for further testing.

\section{Grinding Ratio}

Fresh CS, RS, WS, dewatered SS, and compost samples obtained in different times were used to measure the grinding ratio. Table 1 outlines the basic properties of the materials, and Table 2 lists the maturity and quality parameters of compost samples. Different straws with $30-100 \mathrm{~cm}$ meter length in original were pretreated to $3-5 \mathrm{~cm}$ using scissors. $5.0 \mathrm{~g} \times 8$ of materials (different straws, SS, and compost samples) were weighed respectively and put into aluminum dishes, then dried at $105^{\circ} \mathrm{C}$ for 8 hours. One dish was quickly taken out of the oven every hour to calculate water content. Then the sample was soon passed to the same plant grinder (JK-MPG-102, shanghai). Three replications were performed.

In order to guarantee the same evaluating standard, $1 \mathrm{~min}$ was set to pass a sieve with diameter $1 \mathrm{~mm}$ after samples were ground. The percentage of the sample's mass that passed though the sieve to the total mass of materials before being ground was calculated and defined as grinding ratio. The formula is given by:

$$
\text { Grinding ratio }(\%)=M_{1} / \mathrm{M}_{0} \times 100
$$

...where $M_{1}$ is the samples being ground following passing though the sieve with diameter $1 \mathrm{~mm}$. $\mathrm{M}_{0}$ is the total mass of materials before grinding.

\section{Analytical Method}

Compost analysis was conducted according to the standard examination of composting and compost [25]. Fresh samples were prepared to test moisture, $\mathrm{pH}$ value, and electrical conductivity (EC). Dried samples passed through a sieve $1 \mathrm{~mm}$ in diameter after being ground by a coffee maker to determine total organic carbon (TOC), nitrogen Kjeldahl (N), and phosphate (P). Lignin, cellulose, and hemicellulose were tested by novel Van Soest methods, and detailed information can be found in Peltre [26]. All tests were performed in triplicate and the results are presented as an average value followed by corresponding standard deviation. $\mathrm{C} / \mathrm{N}$ ratio was calculated from the average value of TOC and nitrogen Kjeldahl. Germination index (GI) of the compost was tested by the methods in a previous report by Zhang et al. [27].

\section{Statistical Analysis}

The data were analyzed using Graphpad Prism 6.02. Homogeneity was analyzed via one-way analysis of variance (ANOVA), and differences of grinding ratio were determined by Tukey's multiple comparisons test. All statistical tests were evaluated at the $95 \%$ confidence level. Linear correlations between compost maturity parameters and grinding ratio were also determined. 


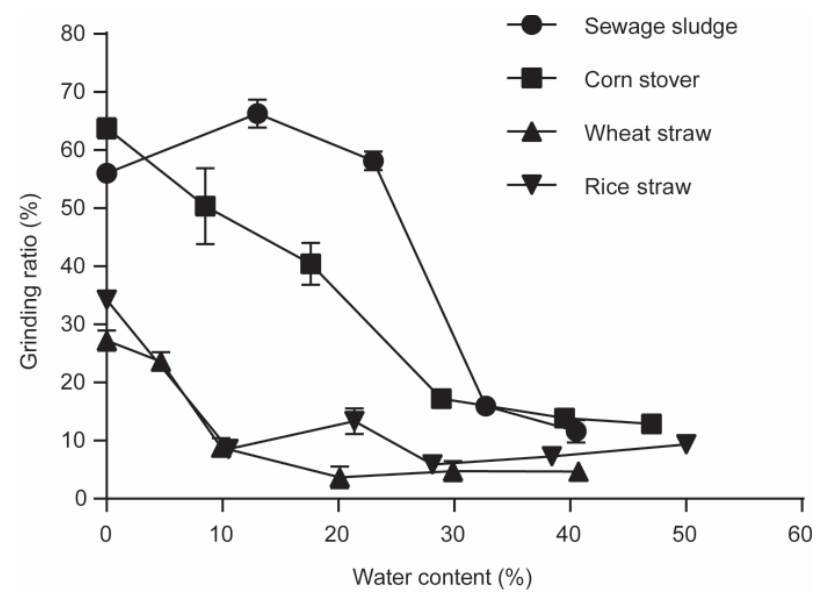

Fig. 1. Grinding ratio of 4 different compost raw materials changing with water content; error bars are standard error (Mean $\pm \mathrm{SD}, \mathrm{n}=3)$.

\section{Results and Discussion}

\section{Compost Raw Materials and Grinding Ratio}

Grinding ratios of four different compost raw materials changing with water content are shown in Fig. 1. Sewage sludge and corn stover had a higher grinding ratio than wheat and rice straw. Moreover, all 3 straws reached a maximum grinding ratio when they were dried into constant weight, and with water content increasing they slowed. Nevertheless, for sewage sludge, grinding ratio was the highest at water content $13.0 \%$, and then decreased sharply when the water content was over $23.0 \%$. The 3 straws showed a decrease in grinding ratio from the highest to the lowest in the following order: corn stover $>$ rice straw $\geqq$ wheat straw. In the case of water content around $10 \%$, the grinding ratio of sewage sludge was even more than corn stover, probably due to the simple mechanical structures and very low contents, and of cellulose, hemicellulose, and lignin in the sewage sludge. It is reported that the 3 components of cellulose, hemicellulose, and lignin form cell walls of plants with complex structure and strong tenacity. With plants aging and withered, the cell wall undergoes secondary thickening and is often lignified, leading to increased physical resistance [14]. In this study, cellulose, hemicellulose, and lignin in all 3 straws accounted for about $72 \%$ on average (Table 1). Further regression analysis suggested that grinding ratio was significantly correlated to cellulose content at $\mathrm{P}<0.01$ and hemicellulose content at $\mathrm{P}<0.05$, but no significant correlation was seen with lignin and grinding ratio $(\mathrm{P}>0.05)$. The summary content of cellulose and hemicellulose was $9.7 \%$ for sewage sludge, $51 \%$ for corn stover, $56.4 \%$ for rice straw, and $61.5 \%$ for wheat straw, respectively, which was negatively consistent with the grinding ratio.

In addition, as shown in Table 1, sewage sludge has the lowest TOC but highest grinding ratio. Paradoxically,

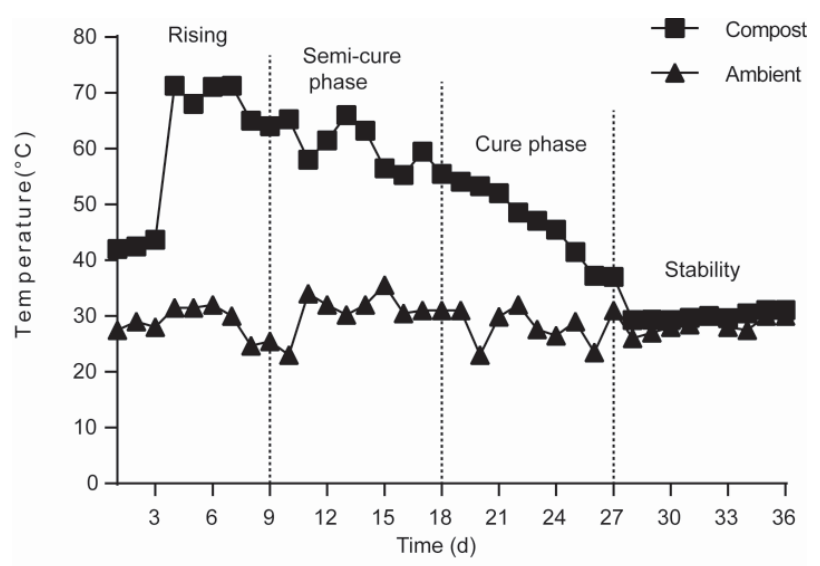

Fig. 2. Four stages of the composting process according to temperature change.

for the 3 straws, grinding ratio showed a decrease with TOC decreasing. It is notable that low $\mathrm{C} / \mathrm{N}$ materials have a higher grinding ratio, indicating that $\mathrm{C} / \mathrm{N}$ was a more important factor impacting the grinding ratio than TOC.

\section{Composting Time and Grinding Ratio}

In terms of temperature changing in the USEPA compost standard [4, 28], composting process in this study was divided into the 4 stages of rising $(0-9 \mathrm{~d})$, high (9-18 d), falling (18-27 d), and stable (27-36 d; Fig. 2). Temperature over $55^{\circ} \mathrm{C}$ lasted for 14 days and the highest temperature reached $72^{\circ} \mathrm{C}$. Grinding ratio of compost samples in different stages reached $80 \%$ when the compost was dried to constant mass (Fig. 3). ANOVA results showed that the grinding ratio of compost at day 0 was significantly lower than for other days (except zero water content in the compost; $\mathrm{P}<0.05)$. We found

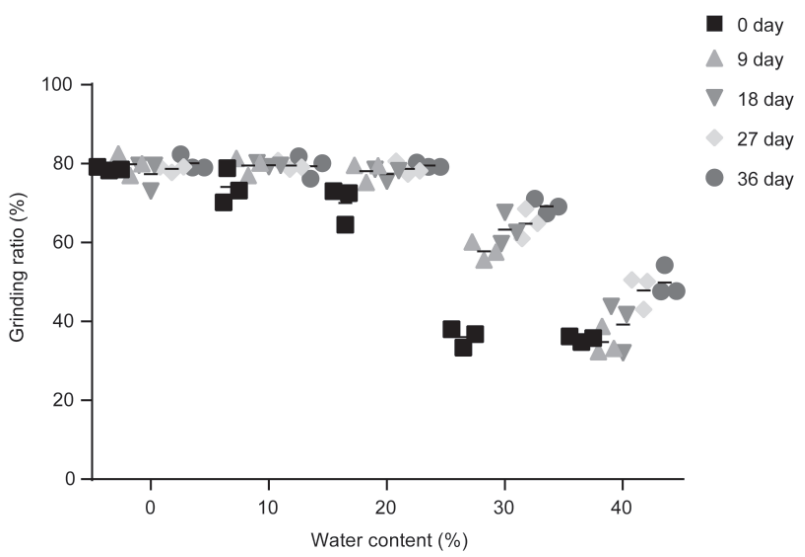

Fig. 3. Grinding ratio of compost changing with water content: (A) samples are grouped from 0-36 day and (B) all bars represent mean values of samples from 0-36 days with standard error; “***” means reaching 0.001 significant $(\mathrm{P}<0.001)$ using oneway analysis of variance (ANOVA), differences of grinding ratio were determined by Tukey's multiple comparisons test . 


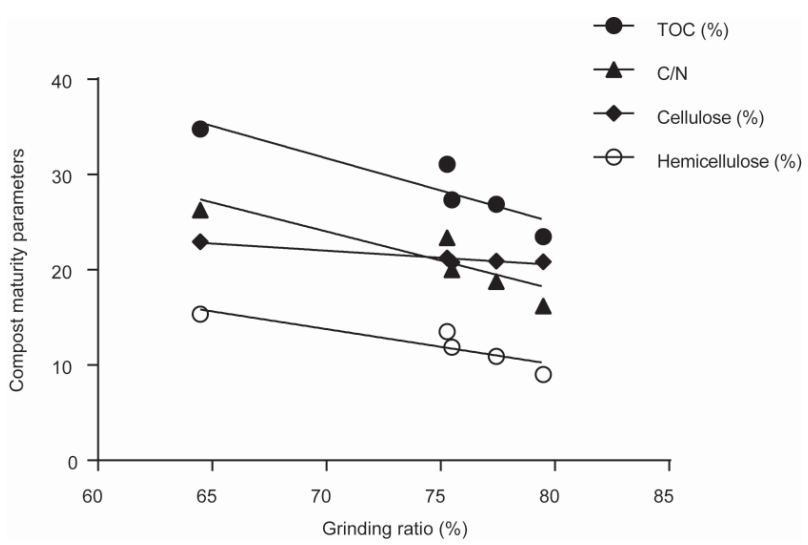

Fig. 4. Regression analysis between grinding ratio and different maturity and quality parameters of compost $(\mathrm{P}<0.05)$.

no significant differences of the grinding ratio among the samples obtained in different fermenting stages when water content was less than $20 \%$ (except zero water content). This result revealed that for compost pelleting in industry production, drying the matured compost to the water content around $20 \%$ could be an efficient way to save energy and investment.

\section{Compost Maturity Parameters and Grinding Ratio}

Table 2 presented a summary of compost parameters tested, which characterized the quality and maturity of the compost. The results revealed that $\mathrm{pH}$ value increased from 7.53 to 8.63 at the beginning, lasting up to 18 days and then tending to fall to 7.53 as composting proceeded. Electronic conductivity has the same tendency with $\mathrm{pH}$. This variation coincides with the amounts of microorganisms who reached peak and then decreased over the composting period [29]. Total organic C, C/N ratio, and contents of hemicellulose and cellulose decreased, which was attributed to the combined action of the increase in microbial population, resulting in the degradation of organic carbon. Aggelis et al. [30] proposed that the substrate was characterized as nonphytotoxic and stable to apply for agricultural purposes if $66<$ GI $<100$. GI increased gradually in this study and the highest value reached $75 \%$ at day 36 , indicating the harmlessness and stability of the compost. Although the content of cellulose and hemicellulose showed down during the composting stages, lignin content first enhanced and then declined to the lowest at day 18 , and then rose again to the highest value of $11.2 \%$, probably due to the 2 insoluble fibers of hemicellulose and cellulose degrading faster than lignin, causing the relative amount of lignin to increase.

As shown in Fig. 4, when the water content was around $20 \%$, regression analysis results indicated that cellulose was highly and negatively correlated with grinding ratio at $\mathrm{P}<0.01$. TOC, $\mathrm{C} / \mathrm{N}$ ratio, and hemicellulose were negatively correlated with grinding ratio at $\mathrm{P}<0.05$, which was probably because TOC determined microbial activity of decomposition and transformation of hemicellulose and cellulose. In contrast, the grinding ratio was not apparently correlated with chemical and biological parameters of $\mathrm{pH}, \mathrm{EC}, \mathrm{GI}$, and lignin $(\mathrm{P}>0.05)$.

\section{Conclusions}

We studied the grinding ratios of different kinds of composting materials (4 raw materials and compost samples with different maturity degrees) and affected factors. The highest grinding ratio was obtained when drying the 3 straws into constant weight, but keeping water content around $10 \%$ for sewage sludge. The grinding ratio of different raw materials decreased from the highest to the lowest in the following order: corn stover $>$ rice straw $>$ wheat straw. The grinding ratio of fermented compost significantly decreased to lower than about $50 \%$ when the water content was higher than $30 \%$, whereas no significant difference was observed when the water content was lower than $20 \%$.

Compared with original materials, mature compost was easier to grind. Further regression analysis implies that grinding ratio had negative linear correlation with TOC, $\mathrm{C} / \mathrm{N}$ ratio, hemicellulose, and cellulose, but no apparent correlation with $\mathrm{pH}, \mathrm{EC}, \mathrm{GI}$, and lignin. This study suggested that for compost pelleting in industrial production, drying the matured compost to the water content around $20 \%$ could be an efficient way to save energy and investment. Given that the content of carbon and nitrogen determines microbial activity and amounts, which impacts decomposition and transformation of hemicellulose and cellulose, further testing could be conducted on the correlation analysis between the grind ratio and microbiology variability in community and amount.

\section{Acknowledgements}

This work was supported by the Doctoral Research Program of Anhui University (project No. J01001932), Anhui Natural Science Foundation (No. 1708085MC67) and the Research Program of Anhui Provincial Education Department (project No. Y05029201) in China.

\section{Conflict of Interest}

The authors declare no conflict of interest.

\section{References}

1. LODHA S., MAWAR R., SAXENA A. Compost application for suppression of Macrophomina phaseolina causing charcoal rot in arid crops. Int. Soc. Hortic. Sci. 18, 1044, 2014. 
2. AWASTHI M.K., PANDEY A.K., BUNDELA P. S., KHAN J. Co-composting of organic fraction of municipal solid waste mixed with different bulking waste: Characterization of physicochemical parameters and microbial enzymatic dynamic. Bioresource Technol. 182, 200, 2015.

3. JINDO K., SONOKI T., MATSUMOTO K., CANELLAS L., ROIG A., SANCHEZ-MONEDERO M.A. Influence of biochar addition on the humic substances of composting manures. Waste Manage. 49, 545, 2016.

4. ISOBAEV P., BOUFERGUENE A., WICHUK K.M., MCCARTNEY D. An enhanced compost temperature sampling framework: Case study of a covered aerated static pile. Waste Manage. 34 (7), 1117, 2014.

5. FANG M., WONG J.W.C., LI G.X. Changes in biological parameters during co-composting of sewage sludge and coal ash residues. Environ. Technol. 64, 55, 1998.

6. JUSOH M.L.C., MANAF L.A., LATIFF P.A. Composting of rice straw with effective microorganisms (EM) and its influence on compost quality. Iranian J. Environ. Health Sci. Eng. 10 (1), 17, 2013.

7. WANG K., LI W.G., GUO J.H., ZOU J., LI Y., ZHANG L. Spatial distribution of dynamics characteristic in the intermittent aeration static composting of sewage sludge. Bioresource Technol. 102 (9), 5528, 2011.

8. RAJ D., ANTIL R.S. Evaluation of maturity and stability parameters of composts prepared from agro-industrial wastes. Bioresource Technol. 102 (3), 2868, 2011.

9. ANTIL R.S., RAJ D. Chemical and microbiological parameters for the characterization of maturity of composts made from farm and agro-industrial wastes. Arch. Agron. soil sci. 58 (8), 833, 2012.

10. NIKIEMA J., COFIE O., ASANTE-BEKOE B., OTOO M., ADAMTEY N. Potential of locally available products for use as binders in producing fecal compost pellets in Ghana. Environ. Prog. Sustain. 33 (2), 504, 2014.

11. ZHANG L., MA H.X., ZHANG H.Q., XUN L.Y., CHEN G.J., WANG L.S. Thermomyces lanuginosus is the dominant fungus in maize straw composts. Bioresource Technol. 197, 266, 2015.

12. MOSTAFID M.E., SHANK C., IMHOFF P.T., YAZDANI R. Gas transport proprties of compost-woodchip and green waste for landfill biocovers and biofilters. Chem. Eng. J. 191 (19), 314, 2012.

13. SAMADI S., EERDENBURG F.J.C.M.V., JAMSHIDIFARD A.R., OTTEN G.P., DROPPERT M., HEEDERIK D.J.J., WOUTERS I.M. The influence of bedding materials on bio-aerosol exposure in dairy barns. J. Expo. Sci. Env. Epid. 22 (4), 361, 8p, 2012.

14. HAO X.D., CAO X.K., HU Y.S. Destruction and degradation of sludge lignocelluloses by pretreatment followed by anaerobic digestion. Acta Sci. Circumst. 34 (7), 1771, 2014

15. ZAFARI A., KIANMEHR M.H. Factors affecting mechanical properties of biomass pellet from compost. Environ. Technol. 35 (4), 478, 2014.

16. ABSALAN G., KIANMEHR M.H., ARABHOSSEINI A. Effective moisture diffusivity and mathematical modeling of drying compost pellet. Agric. Eng. Int. 18 (2), 156, 2016.

17. ESHMETOV I., SALIHANOVA D., AGZAMHODJAEV A. Examination of infulence of the grinding degree and stabilizing agent on the rheological properties of aqua-coal fuel suspensions. J. Chem. Technol. Metallurgy 50 (2), 157, 2015.

18. BATCHELOR A.R., JONES D.A., PLINT S. KINGMAN S.W. Increasing the grind size for effective liberation and flotation of a porphyry copper ore by microwave theatment. Miner. Eng. 94, 61, 2016.

19. SHRECK A.L., NUTTELMAN B.L., SCHNEIDER C.J., BURKEN D.B., HARDING J.L., ERICKSON G.E., KLOPFENSTEIN T.J., CECAVA M.J. Effects of grind size when alkaline treating corn residue and impact of ratio of alkaline-treated residue and distillers grains on performance of finishing cattle. J. Anim. Sci. 93 (7), 3613, 2015.

20. TUMULURU J.S. Specific energy consumption and quality of wood pellets produced using high-moisture lodgepole pine grind in a flat die pellet mill. Chem. Eng. Res. Des. 110, 82, 2016.

21. ZAFARI A., KIANMEHR M.H. Effect of raw material properties and die geometry on the density of biomass pellets from composted municipal solid waste. BioResources. 7 (4), 4704, 2012.

22. BERNABÉ G.A., KOBELNIK M., ALMEIDA S., RIBEIRO C.A., CRESPI M.S. Thermal behavior of lignin and cellulose from waste composting process. J. Therm. Anal. Calorim. 111 (1), 589, 2012.

23. AGARWAL U. Raman imaging to investigate ultrastructure and composition of plant cell walls: distribution of lignin and cellulose in black spruce wood (Picea mariana). Planta. 224, 1141, 2006.

24. BUFFIERE P., LOISEL D., BERNET N., DELGENES J.P. Towards new indicators for the prediction of solid waste anaerobic digestion properties. Water Sci. Technol. 53, 233, 2006.

25. The U.S. Department of Agruiculture and The U.S. Composting Council. Test Methods for the Examination of Composting and Compost (TMECC). Edaphos Int, Houston, TX, 2001.

26. PELTRE C., DIGNAC M.F., DERENNE S., HOUOT S. Change of the chemical composition and biodegradability of the Van Soest soluble fraction during composting: A study using a novel extraction method. Waste Manage. 30, 2448, 2010.

27. ZHANG H., LI G., GU J., WANG G., LI Y., ZHANG D. Influence of aeration on volatile sulfur compounds (VSCs) and $\mathrm{NH} 3$ emissions during aerobic composting of kitchen waste. Waste Manage. 58, 369, 2016.

28. USEPA. Control of Pathogens and Vector Attaction in Sewage Sludge. No.EPA/625R-92/013. Cincinnati, OH: United States Environmental Protection Agency. 2003.

29. SWARNAM T.P., VELMURUGAN A., PANDEY S.K., DAM R.S. Enhancing nutrient recovery and compost maturity of coconut husk by vermicomposting technology. Bioresource Technol. 207, 76, 2016.

30. AGGELIS G., EHALIOTIS C., NERUD F., STOYCHEV I., LYBERATOS G., ZERVAKIS G. Evaluation of white-rot fungi for detoxification and decolorization of effluents from the green olive debittering process. Applied Microbiology \& Biotechnology, 59, 353, 2002 